\title{
Competency of Zimbabwean Teachers Who Completed In-Service Teachers Training Program in Inclusive Education
}

\author{
Patricia Muvirimi \\ Great Zimbabwe University, Zimbabwe \\ trishmuv@gmail.com
}

\begin{abstract}
This qualitative study examined the competency of in-service teachers in inclusive education in Zimbabwe. A purposive sample of 15 graduate in-service special needs education teachers selected from one state university participated in the study. Semi structured interviews were used to collect data. Thematic analysis was used to analyse data. The study established that for most of the teachers, the in service training fairly managed to prepare them adequately to teach in an inclusive class. It was also found from the study that most teachers interviewed are knowledgeable in identifying children with special needs. Peer tutoring and interaction groups were common methods of teaching. It was also reported that lack of resources and lack of support from other teachers were major challenges impeding teachers from meeting the needs of the learners in inclusive setting. The study further revealed that extensive training on use of individual educational program is needed during training. The study recommends that teachers be evaluated on all relevant competences during teaching practise which could enhance the professional development of in-service teachers in inclusive education. Another recommendation is that micro teaching strategy be used to fine tune the teachers skills in teaching in an inclusive classes.
\end{abstract}

Keywords: Competency, In-service teacher training, inclusive education.

\section{Introduction}

Providing a quality education for all students in inclusive settings has been acknowledged as perhaps the most challenging yet most important issue in education (Atta, Shah, \& Khan, 2006). Zimbabwe has aimed, since the 1990s, to actively shift from exclusive to inclusive education in line with trends on the global stage (Musengi \& Chireshe, 2012; Majoko, 2019). The success of inclusive education depends on adequate knowledge and skills of teachers (Flecha \& Soler, 2013; Florian, 2012; Naicker, 2008). Despite this, teacher education for inclusion is a new stride that the education system in Zimbabwe is attempting to achieve. Inservice teacher training is significant because teachers educated in special education tend to be more positively inclined towards inclusion of children with special needs in the classroom. In service training is important because it is concerned with the activities and courses in which a serving teacher may participate for purposes of upgrading his or her professional skills, knowledge and interest, subsequent to initial training (Osamwoyi, 2016). Since the global adoption of inclusion, teacher training has emphasized on the ability of the teacher to understand the characteristics of children with special needs and adapt the curriculum in tandem with their developmental level and interact in the classroom with all children including those with exceptionalities (Bruns \& Mogharreban, 2009). Teachers are required to have understanding of methods for development, management and implementation of the individual educational program. Teachers are expected to collaborate with other stakeholders including families in order to give them the support they need.

Similarly teachers should be knowledgeable and informed about using behavioural interventions and effective classroom management that enhance teaching and learning of all children (Forlin, 2010). Consistent with several other countries including South Africa (Theron \& Pasha, 2015), the United Kingdom (Florian, 2012), United States (Desimone \& Garet, 2015), and Australia (Carroll, Forlin, \& Joblin, 2003 ), Zimbabwe has institutionalized measures to develop in-service teacher competency in inclusive education. Some Universities and teachers training colleges are now offering in-service programs in inclusive education. This state university offers in-service bachelors of education in special needs education degree. It is a 3 year programme targeted to in-service teachers who had at least a 3 year diploma in education from an associate teachers college of the University of Zimbabwe. Unlike traditional teaching programs special education degree focus on overcoming the challenges of teaching children with special needs. The programme constituted the following modules; foundations and cultural issues in SNE, assessment issues in SNE, curriculum management, guidance and counselling, rehabilitation and transition of children and youth with 
disabilities. Course work in instructional strategies for children with varying special needs like hearing and visual impairment, intellectual disability, learning disability, gifted and talented, physical and motor disabilities, health related disabilities.

Research Objectives: The study had the following objectives;

- To explore the teacher competences after training in special needs education.

- To establish skills being used by the in-serviced teachers.

- To establish future training needs.

\section{Literature Review}

Several international and Zimbabwean studies have examined the competencies of in-service teachers in inclusive education. In a quantitative study with 176 teachers in Ghana, found that these teachers had no exposure to special needs education in their in-service training (Agbenyega \& Deku, 2011). Resultantly, they could not meet the individual needs of learners with disabilities in regular classes. It is evident that the complexity of teacher work, demands competences for everyday dealing with student learning, emotional and behavioural characteristics (Bukvic, 2014). This is especially true for teachers who cater for children with special educational needs that result from sensory, physical, behavioural, intellectual (cognitive) and learning disabilities. Inclusive education means full inclusion of children with exceptionalities (giftedness and disabilities) in all aspects of schooling that other children are able to access and enjoy (Kusuma \& Ramdevi, 2013). Teacher competency is the ability to plan, control and facilitate appropriate interaction in the classroom, while taking into account the different needs and abilities of learners (Dyson \& Squires, 2016).

These competences are explained as a complex combination of different knowledge, skills, understanding, values, attitudes and desire which lead to effective, embodied human action in the world, in a particular domain (Crick, 2008). It is, therefore important to understand that teacher competences are continually evaluated through the interaction with co-workers, student, parents and others. Teaching competencies are thus a complex combination of knowledge, skills, understanding, values and attitudes leading to effective actions in situations of learning. Another study found out that the perceived key competences for successful inclusion are screening and assessment, differentiation of instruction, classroom and behaviour management and collaboration (Majoko, 2019). Researches elsewhere reiterated the key areas of teacher competences as identification of children with special needs, planning to meet the needs, relevant material resources, instructional approaches, assessment and evaluation and effective collaboration with necessary stake holders (Cate, Markova, \& Krischler, 2018). Teachers who have training in special needs education are pivotal in innovatively and collaboratively responding to the unique learning needs of all students.

Screening and Identification: Screening and identification of children with diverse needs is an important teacher competency in inclusive education. Referral and assessment procedures information, aids teachers in identification of children who require differentiated instruction and intensive instruction. Also knowledge of common characteristics of different exceptionalities was ranked as the most vital competence for inclusive education (Dingle, Falvey, Givner, \& Haager, 2004). It is a key competency for the teacher to have extensive knowledge of the various types of behavioural, physical and psychological impairments that may affect students, and the effect of such impairments on children's education, development and quality of life. The teacher should be able to identify children who are in need of additional support due to exceptionalities, including gifted children or those with learning disabilities. Identification of learners with special needs is the first step in accommodating the learner in to the mainstream education setting.

Curriculum Differentiation or Individualised Instruction: Planning to meet the needs involves making curriculum and environmental adaptations. A teacher in an inclusive setting should be able to engage in the inclusion-with-modifications model. The program also incorporates practical teaching experience to facilitate the transfer of learned skills and knowledge to the reality of inclusive classrooms. It is therefore important to explore the competences of teachers who went through the 3 year in-service program. This study will assistant in explicating what competences to be included in in-service teacher training that prepares teachers to work in inclusive settings. The current study addressed the following research question what are the current teacher competencies of the in-serviced special needs education teachers? Appropriate curricula and 
organizational arrangements are central in ensuring quality education for all in an inclusive classroom. The teacher in an inclusive setup should create an enabling environment for inclusive education (Atta, Shah, \& Khan, 2006). It is also imperative for the teacher to be able to plan appropriate arrangements and adaptations of classroom physical environment (Kusuma \& Ramdevi, 2013).

Curriculum adaptation is an on-going dynamic process that modifies and adapts the prescribed program of studies to meet the learning requirements of a student with special needs. The teacher in an inclusive class is expected to use different methods of teaching accommodating both different styles of learning and rates of learning. The use of the individual educational plan is important teaching technique that gives the teacher the right and responsibility to adapt the curriculum to meet the student individual needs. The teacher is expected to be able to instruct students in ways that permit them to master content at a pace suited to their abilities, needs and interests. A competent teacher in an inclusive classroom should be able to design a variety of alternative teaching strategies in order to compensate the deficient area of SEN children (Kusuma \& Ramdevi, 2013). In the process of designing alternative teaching strategies the teacher employs adaptive instruction which requires teachers to assess the characteristics and capabilities of each student, collaborate and consult with others to plan developmentally appropriate instruction (Wang, 1984). This means the teacher should be able to instruct students in ways that permit them to master content at a pace suited to their abilities, needs, and interests.

Assessment and Evaluation: One key teacher competency is the use of evaluation data to assess the attainment of goals set in Individualised Education Plan and to set new goals (Kusuma \& Ramdevi, 2013). Teachers may assess special needs student in the inclusive class by providing multiple test formats. An effective teacher in an inclusive class will collect data through notes, checklists, sticky notes, and audio notes in order to keep track of student strengths and needs (Eredics, 2018).

Collaboration: In order to provide adequate education for scholars with special needs the teacher should seek out consultative relationship with support personnel. This requires the teacher to take a holistic approach to the education of student, in particular students with special needs (Majoko, 2019). Competent teachers simultaneously translate theory into practice and consider the learner population and the sociocultural contexts in which teaching and learning take place (Majoko, 2019). This means that the competent teacher collaborates with other relevant stakeholders such parents and other professionals (psychologists, social workers, occupational therapists and speech therapists) to cater for the needs of every learner. Collaborative problem solving between teachers and other support professionals promotes inclusive education (Atta, Shah, \& Khan, 2006). The teacher should build stable and cooperative with support personnel, parents and other stakeholders for procurement of relevant special educational material. This will assist in creating an optimal learning experience for children with special needs. A study of Australian teachers revealed a grave concern pertaining to the lack of support services available to the students and themselves and disclosed a perceived inability to provide optimal educational program to children with special needs because of inadequate teacher preparation and lack of adequate resources (Carroll, Forlin, \& Joblin, 2003).

Classroom Management/Behaviour Management: Several studies show that currently, instruction in inclusive settings is inadequate and usually does not meet the needs of diverse children with special needs (Majoko, 2019; Kuyini \& Mangope, 2011; Selvi, 2010). Research reveals that there is inadequate training of teachers on inclusive education as well as the appropriate differential instruction for a class with learners with diverse needs. This necessitates the examination of the competencies that teachers require to meet the needs of children. In their investigation of 20 inclusive classrooms, established that several teachers utilized very few adaptive teaching strategies in their delivery of lessons in regular classrooms (Kuyini \& Desai, 2008) in another study, established that adapting instructional materials, behaviour management among others were important competences and also availability of teaching materials, support teachers, more training as key support resources which may enhance in the classroom (Kuyini \& Mangope, 2011).

Similar findings by) revealed that children with special needs are not likely to benefit from the teaching and learning opportunities offered in regular classrooms (Agbenyega \& Deku, 2011). In the United States and Europe it is generally stated that effective inclusive practise requires teachers to be able to deliver specialised 
instructional practice geared towards the individualised needs of all students (Oddome, 2016; Watkins, 2012). Due to their unique characteristics learners with special needs may require to be taught certain subjects over and above those detailed in the regular school syllabus. Such subjects include typing, orientation and mobility, activities of daily living skills, perceptive training, sign language and individual speech training (Kigen, 2017). Therefore adequately trained professionals are required in the provision of meaningful educational services to children with special needs in an inclusive class. Qualitative methodology provides a systematic avenue to comprehend complex phenomena and events within a specific context.

\section{Methodology}

This makes it an ideal way to generate scientifically based evidence and insight to inform practice in educations and provide the basis for future research within the qualitative research approach a case study design was employed (Mcmillan \& Schumacher, 2010). Graduates from a state university who were full time were targeted for the purposes of evaluating the in -service training program. Purposive sampling was used in selecting the participants. Data was collected using semi structured telephone interviewing technique. Interviews gave the participants a chance to express their experiences freely. Telephone interviewing was utilised for its convenience as the participants are scattered in different geographical locations where they work. Interviews allows for the collection of word rich information (Yin, 2014). In this study the concern was to investigate/or explore the special needs education related competences and training needs of individual teachers to build up a picture of the general situation of teacher competencies and training needs. Qualitative data analysis was used to analyse the data using the following steps, data reduction, coding and categorization into themes (Creswell, 2013). The major themes that emerged from the data were supported verbatim quotes when necessary.

Ethical Considerations: In any research study researchers demonstrate integrity and competence. Aspects of trustworthiness and ethics were considered to uphold rigor. As a way of observing ethics, informing participants of the purpose of study as well as the freedom to withdraw was done. Names of the participants were not to be revealed for anonymity reasons.

Sampling: Purposive sampling was used to select 15 participants who are former students at the state University who specialized in special needs education, and had at least two years-experience teaching children with disabilities in an inclusive class. This is because it is assumed that they had managed to put special needs education theory that they had learnt in to practice in the work environment.

\section{Results and Discussion}

This section discusses the major findings of the study based on the research questions of the study. The following themes were generated from the data collected;

Knowledge Dimension: It was revealed that training provided the teachers with the ability to identify students with special needs. Respondents reported that they are able to detect and deal with children with intellectual disabilities, visual impairment, hearing impairment, learning disabilities, autistic, epilepsy, physical cerebral palsy and emotional dyslexia. This confirms views that, extensive knowledge of the various types of special needs and the effects of such in child development is an essential element of inclusive education (Dingle, Falvey, Givner, \& Haager, 2004). All respondents correctly reported that they can identify children with special needs by observation, physical appearance, and testing through academic performance. Therefore the ability to identify special needs of children was a vital competence for inclusive teaching. When asked about policies and legislation that guide provision of special needs education, most teachers who graduated from the in-service training programme indicated an awareness of policies and legislation that guide special needs education in the country. Most teachers reported knowledge of the Education Act 2006, Constitution of Zimbabwe 2013, and the Secretary's Policy Circular p36 of (1990). Only a few of the respondents mentioned the Salamanca statement of 1994.

Curriculum Differentiation/Individualised Instruction: Results showed that all teachers could make curriculum and environmental adaptations depending on the special need identified. This is also evident 
enough that they have mastered the ability to transfer theory to real work practise. Curriculum adaptations reported by most respondents include children writing less and different work, individual exercises, content, methodologies, large print for low vision, planning separately using individual instruction plan, simplifying content, breaking down matter into teachable units, task analysis and exam modification. Some respondents professed the use of peer tutoring, buddy systems and interaction groups where children with special needs have models to imitate. Environmental adaptations reported included making rumps, front seating positions, rails and ramps for children with visual impairment, raised tables, larger desks for braille books, inclusive toilet and closing potholes in classrooms. This is in line with the recommendation made that a teacher in an inclusive setup has to create an enabling environment for inclusive education (Atta, Shah, \& Khan, 2006). However, A few respondents who reported making ramps as environmental adaptations did not report having children using wheelchairs in their classrooms.

Provision of the necessary physical facilities like ramps and rails for children with physical impairments in schools is necessary. It is those with specialist knowledge in inclusive education who should make such recommendations to the school authorities. All respondents reported use of individual education plan for learners with special needs. The popular methods included giving the students individual attention, planning and teaching one on one, check learners' progress, drafting learning program for each child and assess learner's performance and plan suitable work from point of mastery. However, one respondent reported that the school's psychological services department was not providing the required assistance; hence she was facing challenges in implementing her knowledge. This calls for the need for all stakeholder involvement in special need education. Reports on material resources being used by teachers indicate that some suitable materials are being used. Material resources being used include ICT tools, mobile visuals, computers, braille machines, and large print books, projectors, learning blocks, real objects, charts and sign language charts. The issue of quantity of the material resources was raised. However, the major challenge in using these materials is the rampant power load shedding that the country is experiencing as reported by most respondents.

Instructional Competence: All respondents could name at least two teaching approaches they used in an inclusive class. The approaches included use of games, songs, look and say, storytelling, child centred approach, pair work, peer tutoring, experimenting, role play dramatization projects, multisensory approach, cooperative learning, direct instruction, mobility and discovery learning. These approaches are meant to enhance cognitive, social and emotional development within a cultural context, one of the core issues in the University's curriculum. A teacher in an inclusive setting is expected to use different methods of teaching for successful inclusion. In most of the responses however, a respondent indicated using at most two methods. In evaluation of the students' academic performance, also proposed use of multiple formats in order to keep track of student's strengths and needs (Eredics, 2018). Most respondents reported using one or two formats of assessment. The use of various formats is important as one format can address the weaknesses of another. A highly competent teacher puts into practise a number of assessment formats. The formats of evaluation reported by most respondents include writing exercises and making use of assessment tests, group work activity, classroom assessment, assignments, criterion tests and curriculum-based tests. One respondent in particular reported multiple Assessment formats, he reported that: Assessment of progress of all learners is done through observation and recording, oral and written tests, daily exercises, tests, group work activity, and continuous assessment.

Collaboration: Most of the respondents reported stakeholder participation as important in inclusive education. The respondents reported collaborating with parents, other teachers and professionals. However, a very few respondents reported lack of stakeholder participation. These reported lack of corporation from other teachers, the school's psychological services department, lack of parental cooperation, and lack of support from school administration. Collaboration with stakeholder participation is important as inclusive education requires a holistic approach to ensure its success (Majoko, 2019). In his findings he established that collaboration is a key competence in inclusive education. A competent teacher should be aware of the communication techniques to ensure collaboration. When asked about areas of collaboration with parents the participants reported issues including welfare of the learners, in writing ecological inventories, in behaviour management, teaching and modifying behaviour, in staff development, homework, writing social record, transportation, identifying children with special needs out of the school and monitoring the learners. Other 
important stakeholders identified by respondents were remedial tutors, educational psychologists, doctors, nurses, police, counsellors, schools' psychological services personnel, audiologists and opticians.

Challenges Experienced in Meeting the Children's Needs: Most respondents reported lack of resource as the major challenge faced in meeting the learning, behavioural, emotional and psychological needs of children. Half of the respondents reported lack of time and assistive devices as a crippling challenge. One respondent in particular said "children with special needs are not prioritized both at home and at the school" Several challenges were encountered by teachers when teaching and interacting with learners in an inclusive class. Challenges reported included modifying behaviour, inadequate resources, communicating and engaging with the children with hearing impairment, maths teaching using braille, meeting the needs of all the learners, grouping, large class size and use of IEP. The above concurs with the finding which reveal that inclusive education is met with a number of challenges in implementation such as those reported by the participants (Kuyini \& Desai, 2008). I am now able to handle cases that involve learners with special needs, offer assistance to my counterparts, and guide children with special needs to achieve their optimal performance.

Teachers Perception of the In-Service Program: Most of the teachers interviewed reported that the specialist training prepared them adequately to teach children in an inclusive classroom. The respondents reported that they have been equipped with the ability to manage the curriculum and learning environment for the sake of students with special needs. They were also able to translate different learning theories to practise, and collaborate with some stakeholders. One respondent in particular said: the program has been of much relevance to my work. However, a small number of the respondents interviewed responded by saying that their training in special needs education had not adequately prepared them. These felt that they are still finding it difficult to teach children with hearing impairment because the program was mostly theoretical.

One respondent had this to say: the training had been mostly theoretical; I had no opportunities to actually visit people with disabilities during the training. Another respondent said: I lacked practical experience because I did not manage to carry out my teaching practice at schools that have special need education in line with the training requirement as a result of logistic problems. When asked about how they solve problems encountered, most of the teachers reported that they consulted specialists and seek advice from more experienced teachers. Contacting parents was also cited as a strategy of problem solving. Teachers also instigated that when they encountered problems, they would inform the administration and some consult journals as problem solving strategies. Some reported that they would work out solutions for themselves while others indicated that they would seek advice from colleagues.

Future Needs: Teachers reported the need to further training in the development and use of the IEP, communication techniques and sign language. Some of the respondents indicated they needed more information about autistic children. Further expressed need for teaching guide for inclusive practices, teaching aids. Another group of teachers reported that there was need for exposure to children and adults with disabilities.

Recommendations: An all-inclusive approach, where all stakeholders must be involved must be implemented so that inclusive education does not only become the role of those with specialist training, this will ensure cooperation and buy in from relevant stakeholders. It is also recommended that teachers should be evaluated in all teaching methods so that they develop multiple skills in teaching children with special needs and in assessing them. The use of micro teaching during training and exposure to children with special needs is also recommended. It is further recommended that the government make it a policy to include inclusive education in the general education curriculum to enhance cooperation from other teachers in general in as much as inclusive education is concerned. 


\section{References}

Agbenyega, J. \& Deku, P. (2011). Building new Identities in Teacher Preparation for Inclusive Education in Ghana. Current Issues in Education.

Atta, M., Shah, M. \& Khan, M. (2006). Inclusive School and Inclusive Teacher. University of Peshawar.

Bruns, D. \& Mogharreban, C. (2009). The Gap between Beliefs and Practices: Early Childhood practitioners' perceptions about inclusion. Taylor \& Francis online.

Bukvic, Z. (2014). Teacher competency for inclusive Education. The European Journal of Social and Behavioural Science, (R)ISSN, 2301-2218.

Carroll, A., Forlin, C. \& Joblin, A. (2003). The impact of teacher training in special education on the attitudes of Australian pre-service general educators towards people with disabilities. Teacher Education Quarterly, 30, 65-79.

Cate, P., Markova, I. \& Krischler, M. (2018). Promoting inclusive Education: The Role of teachers' competence and attitudes. Insights into Learning Disabilities, 15(1), 49-63.

Creswell, J. (2013 ). Research design; Qualitative, quantitative and mixed method approaches. Sage Publications.

Crick, R. (2008). Key Competences for Education in a European Context: Narrative of Accountability or Care. European Educational Research Journal, 7(3).

Desimone, L. \& Garet, M. S. (2015). Best practice in teachers'professional development in the United States. Psychology, Society and Education.

Dingle, M., Falvey, M., Givner, C. \& Haager, D. (2004). Essential Special and General Education teacher competences for preparing Teachers for Inclusive Settings. In Issues in Teacher Education, 13(1), 3550.

Dyson, A. \& Squires, G. (2016). Early school learning and learners with disabilities and /or special educational needs. European Agency for Special Needs \& Inclusive Education.

Eredics, N. (2018). Inclusion in Action,. Baltimore: Brooks Publishing Company.

Flecha, R. \& Soler, M. (2013). Turning difficulties into possibiities: Engaging Roma families and students in school through dialogic learning. Cambridge Journal of Education - Taylor and Francis online.

Florian, L. (2012). Preparing teachers to work in Incusive Classrooms: Key lessons for the professionlal development of Teacher Educators from Scotland. Sage: Journal of Teacher Education.

Forlin, C. (2010). Reframing Teacher Education for Inclusion. In C. Forlin, Teacher Education for Inclusion; Changing paradigms and Innovative approaches, 3-12.

Kigen, J. (2017). Teacher Competencies in Implementation of Curriculum for learners with special needs in Kenyan Schools. IOSR Journal of Research \& Method in Education.

Kusuma, A. \& Ramdevi, K. (2013). Inclusive Education- Teacher Competences. Shanlax International journal of Education, 1(3), 2320-2653.

Kuyini, A. (2016). Ghananian teachers competences perceived as important for inclusive education. . International Journal of Inclusive Education.

Kuyini, A. \& Desai, I. (2008). ProvidinInstruction to students with special needs in Inclusive Classrooms in Ghana: Issues and Challenges. International journal of whole schooling, 4.

Kuyini, A. \& Mangope, B. (2011). Student Teachers'attitudes and concerns about inclusive education in Ghana and Botswana. International Journal of Whole Schooling, 7.

Majoko, T. (2019). Teacher key competencies for Inclusive Education: Tapping pragmatic Ralities to Zimbabwean Special Needs Education. Sage.

Mcmillan, J. H. \& Schumacher, S. (2010). Research in Education. Evidence-Based Inquiry, 7th Edition. Virginia Commonwealth University.

Musengi, M. \& Chireshe, R. (2012). Inclusion of Deaf Students in mainstream rural primary schools: Challenges and opportunities. Studies of Tribes and Tribal.

Naicker, J. (2008). Educators' preparedness for Inclusive Education (Doctoral dissertation). Education Resources Information Centre.

Oddome, F. (2016). Self efficacy: A booster for pedagogical Innovation. Journal of E-learning and knowledge Society, 12(3).

Osamwoyi, E. (2016). In service of Teachers: Overview, Problems and the way forward. Ekiadolor-Benin: Tayo Akpata University of Education. 
Selvi, K. (2010). Teachers' Competencies. Cultura International Journal of Philosophy of Culture and Axiology.

Theron, C. \& Pasha, N. (2015). Cultural Pathways to Resilience: Opportunities and Obstacles as recalled by Black South African Students. Dordrecht. Springer.

Wang, M. (1984). Effective Special Education in Regular Classes. Remedial and Special Education; Sage, 5(6).

Watkins, P. (2012). Teacher Education for Inclusion; A Profile of Inclusive Teachers. European Agency for Development in Special Needs.

Yin, R. (2014). Case Study Reasearch Design and Methods: 5th Ed. Thousand Oaks: Sage. 